\title{
PESSOA COM DEFICIÊNCIA INTELECTUAL: A NOVA "RALÉ” DAS ORGANIZAÇÕES DO TRABALHO
}

\author{
PEOPLE WITH INTELLECTUAL HANDICAPS: THE NEW 'WORKING-CLASS BRATS” OF LABOR \\ ORGANIZATIONS
}

PERSONA CON DEFICIENCIA INTELECTUAL: LA NUEVA "RALEA" DE LAS ORGANIZACIONES DEL TRABAJO

\section{RESUMO}

Como a questão social é uma discussão atual nos estudos organizacionais, este artigo analisa a promoção da igualdade de oportunidade para trabalhadores com deficiência intelectual no contexto das organizações modernas, tomada do ponto de vista da racionalidade como orientadora das suas práticas. A análise faz-se com base na ação afirmativa, estabelecida em lei, que obriga as organizações do trabalho com mais de 100 funcionários a empregarem pessoas com deficiência, da definição de deficiência intelectual e das práticas de gestão de pessoas como promotoras dessa igualdade. Foram utilizados a metodologia qualitativa e o referencial da teoria de racionalidade. Os resultados mostram que as práticas de gestão desses trabalhadores têm como base a racionalidade instrumental. Finalmente, o artigo mostra que não há igualdade de oportunidade para essas pessoas no mercado de trabalho e que as práticas de recursos humanos precisam modificar-se para serem promotoras dessa igualdade.

PALAVRAS-Chave Pessoa com deficiência intelectual, igualdade de oportunidades, racionalidade instrumental, racionalidade substantiva, gestão de pessoas.

Sérgio Sampaio Bezerra executivo@apaebrasil.org.br

Mestre em Gestão Empresarial pela Escola Brasileira Escola Brasileira de Administração Pública e de Empresas, Fundação Getulio Vargas - Rio de Janeiro - RJ, Brasil

Marcelo Milano Falcão Vieira (in memoriam)

Professor da Escola Brasileira Escola Brasileira de Administração Pública e de Empresas, Fundação Getulio Vargas - Rio de Janeiro - RJ, Brasil

\begin{abstract}
As social issues became part of current organizational studies, this essay analyses the promotion of equal opportunities to mentally challenged workers in the context of modern organizations, taking rationality as a guiding principle of their practices. The analysis is based on the affirmative action provided by the law, which obliges companies with more than 100 employees to hire people with disabilities, according to the definition of mentally challenged people and to the management practices that promote equal opportunities. This study applies the qualitative methodology and the theory of rationality. Results show that the management practices of these workers have the instrumental rationality as basis. The conclusion is that this group does not have access to the same job opportunities and that human resources practices should change in order to promote equality.

Keywords Mentally challenged people, equal opportunities, instrumental rationality, substantive rationality, people management.

Resumen Como la cuestión social es una discusión actual en los estudios organizacionales, este artículo analiza la promoción de la igualdad de oportunidades para trabajadores con deficiencia intelectual en el contexto de las organizaciones modernas, tomada del punto de vista de la racionalidad como orientadora de sus prácticas. El análisis se hace con base en la acción afirmativa, establecida en ley, que obliga a las organizaciones del trabajo con más de 100 empleados a emplear personas con deficiencia, en la definición de deficiencia intelectual y en las prácticas de gestión de personas como promotoras de esa igualdad. Fueron utilizados la metodología cualitativa y el referencial de la teoría de racionalidad. Los resultados muestran que las prácticas de gestión de esos trabajadores tienen como base la racionalidad instrumental. Finalmente, el artículo muestra que no hay igualdad de oportunidades para esas personas en el mercado de trabajo y que las prácticas de recursos humanos deben modificarse para ser promotoras de esa igualdad.

Palabras clave Persona con deficiencia intelectual, igualdad de oportunidades, racionalidad instrumental, racionalidad sustantiva y gestión de personas.
\end{abstract}




\section{INTRODUÇÃO}

A relação da sociedade com a deficiência modificou-se ao longo do tempo. Atualmente, há o reconhecimento de que a pessoa com deficiência é cidadã como qualquer outra, com o mesmo direito à livre escolha e a usufruir das oportunidades disponíveis na sociedade, qualquer que seja seu tipo de deficiência e o grau de comprometimento que apresente, cabendo à sociedade reorganizar-se, para garantir a qualquer um, independentemente das peculiaridades individuais, acesso a tudo que a constitui e a caracteriza. É nesse contexto que se começa a discutir a inserção da pessoa com deficiência no mercado do trabalho.

Para promover a inserção desses indivíduos no mundo do trabalho, a legislação brasileira estabeleceu uma reserva legal de cargos, conhecida como Lei de Cotas (art. 93 da Lei n. 8.213/91). Esta determina que a empresa privada com 100 ou mais empregados preencha de $2 \%$ a $5 \%$ dos seus cargos com beneficiários reabilitados ou com pessoas deficientes, habilitadas, na seguinte proporção: de 100 a 200 empregados, 2\%; de 201 a 500, 3\%; de 501 a $1.000,4 \%$, e, de 1.001 em diante, $5 \%$.

O fato de essas pessoas estarem contratadas pelas organizações não significa, necessariamente, que haja efetiva igualdade de oportunidades. No mundo do trabalho, o reconhecimento dos trabalhadores dá-se pela sua utilidade, por seu rendimento monetário e por seu valor comercial (PAGÈS e outros, 2006). Nela, a seleção para o emprego e o desempenho do funcionário não dependem da boa vontade de um patrão compreensivo. Essa objetivação leva à submissão dos indivíduos a regras e a uma lógica própria das organizações modernas, que têm nas políticas de gestão de pessoas o mecanismo essencial que permite tal submissão. As práticas de gestão de pessoas, então, têm um papel fundamental e devem ser adaptadas às especificidades do trabalhador com deficiência se, de fato, se quer uma real inclusão dessas pessoas nas organizações e no mercado de trabalho.

A questão torna-se ainda mais complexa quando se discute a igualdade de oportunidades no mercado de trabalho para a pessoa com deficiência intelectual. Considerando que essas pessoas têm significativas limitações cognitivas, pode-se supor que a racionalidade que orienta as ações nas organizações modernas (Weber, 1983) faz com que seu desempenho seja considerado sofrível. Nesse sentido, a definição da deficiência intelectual tem um papel fundamental, pois é a com base nisso é que se poderá, ou não, inserir esse público no mercado de trabalho. Nas duas últimas décadas, a
Associação Americana de Deficiência Intelectual e Desenvolvimento (AADID) tem evidenciado a importância da definição do conceito. Segundo essa associação, a deficiência intelectual é:

\footnotetext{
Uma incapacidade caracterizada por importantes limitações, tanto no funcionamento intelectual quanto no comportamento adaptativo, e está expressa nas habilidades adaptativas conceituais, sociais e práticas. Essa incapacidade tem início antes dos 18 anos (AMERICAN ASSOCIATION ON MENTAL RETARDATION, 2002, p. 20).
}

De acordo com Goyos e Araújo (2006), essa nova definição ampliou o conceito de comportamentos adaptativos, estendendo-o a três componentes: o conceitual, o social e o prático. Na área conceitual, é a linguagem (receptiva e expressiva); a leitura e escrita; conceito de dinheiro e autodireção. Na área social, a interpessoalidade; obediência a regras, responsabilidade; respeito às leis; autoestima; evitar vitimização; ser enganado e/ ou manipulado e a ingenuidade. Na área prática, são as atividades de vida diária e vida prática; habilidades ocupacionais e a manutenção da segurança nos ambientes. O desempenho baseado nos comportamentos adaptativos é a chave para o sucesso desses indivíduos, estando intrinsecamente relacionado ao grau de necessidade de apoio de cada um.

Diante disso, o objetivo deste artigo é a análise de práticas de promoção da igualdade de oportunidades para trabalhadores com deficiência intelectual no contexto das organizações modernas, tendo como pressuposto a racionalidade que as orienta. Nesse sentido, analisam-se as práticas de gestão de pessoas como promotoras da igualdade de oportunidades por meio das adaptações realizadas na comunicação e na descrição de cargo para inserção do deficiente intelectual no mercado de trabalho. Tendo isso em vista, foram investigados os indicadores de recrutamento e seleção, de treinamento, de avaliação de desempenho e de análise de cargo, bem como os atributos das racionalidades instrumental e substantiva que sustentam essas adaptações.

\section{A RACIONALIDADE COMO ORIENTADORA DAS AÇÕES NA ORGANIZAÇÃO}

O conceito de razão, que, na sociedade moderna, está vinculado à emancipação humana, permitiu ao homem 
produzir cultura e diferenciar-se dos outros animais. Kant (1989) forneceu à humanidade os instrumentos para que possa distinguir os tipos de razão, conforme pode ser lido no prefácio de sua obra publicada originalmente em 1781: "Nada é mais comparável do que deduzir as leis que determinam aquilo que deveria ser feito daquilo que é feito, ou impor a tais leis os limites a que se circunscreve aquilo que é feito".

Kalberg (1980), entendendo por racionalidade o processo pelo qual metas devem ser atingidas dentro de um limite determinado por condições e regras, identifica quatro tipos de racionalidade definidas por Weber: racionalidade prática, racionalidade teórica, racionalidade substantiva e racionalidade formal. Esses tipos de racionalidade manifestam uma multiplicidade de processos de racionalização, orquestrados em todos os níveis de sociedade e processos de civilização. A dominação dos processos de racionalização, nas modernas sociedades ocidentais, implica consequências para os tipos de pessoas que vivem nessas comunidades.

As ações sociais baseadas na racionalidade - prática e teórica - são determinadas por estados emotivos ou sentimentais e também por costumes, sendo nula ou escassa a avaliação sistemática de suas consequências (RAMOS, 1983).

A racionalidade substantiva está ligada à noção de liberdade e de emancipação, não considera o valor utilitário, não é imediatista e está no cerne da formação dos grupos sociais, os quais se organizam de acordo com um consulado de valores. Pautadas por essa racionalidade, as ações sociais são orientadas pelos valores.

A racionalidade formal também é chamada de instrumental ou funcional e está relacionada aos fins. Nela predomina a instrumentalização da ação social dentro da empresa. Esse predomínio é centralizado na formalização mecanicista das relações sociais, em que a divisão do trabalho é um imperativo categórico pelo qual se procura justificar a prática administrativa dentro dos sistemas sociais organizados.

É a racionalidade específica da organização que caracteriza a sua estrutura e as suas ações, constituindo-se no elemento central de sua definição, diferenciando-a das demais; ou seja, a racionalidade é o conceito central para definir uma organização. Pressupõe-se que as empresas sejam estruturadas com o objetivo de atingir seus resultados, maximizando a relação custo/beneficio. Nesse sentido, existe uma racionalidade meio-fim que orienta a lógica organizacional das empresas, que não considera os efeitos que estas possam causar nas pessoas nem se estão cometendo transgressões éticas
(VIEIRA, 2008). Segundo Kalberg (1980), somente a racionalidade substantiva possui atributos éticos, sendo a única racionalidade capaz de se contrapor ao desenvolvimento de racionalidades baseadas num agir puramente instrumental.

Com base nesses pressupostos teóricos, vários autores da área de estudos organizacionais têm se dedicado às pesquisas que procuram identificar a predominância de um caráter substantivado (ou instrumental) nos mais diversos tipos de empresas (DIAS e DELLAGNELO, 2008).

Vários esforços também têm sido feitos na tentativa de entender a razão das ações humanas no interior das organizações produtivas. Serva (1997) realizou pesquisa na qual, baseado nos estudos de Guerreiro Ramos e de Jürgen Habermas, da perspectiva da complementaridade, define os tipos de ação racional e seus respectivos elementos presentes nas organizações produtivas. Para Serva (1997, p. 22), a ação racional substantiva é:

\begin{abstract}
a ação orientada para duas dimensões: na dimensão individual, que se refere à autorrealização, compreendida como concretização de potencialidades e satisfação; na dimensão grupal, que se refere ao entendimento, na direção da responsabilidade e satisfação sociais.
\end{abstract}

Do mesmo modo, Serva (1997, p. 22-23) define ação racional instrumental como a "ação baseada no cálculo, orientada para o alcance de metas técnicas ou de finalidades ligadas a interesses econômicos ou de poder social, através da maximização dos recursos disponíveis".

As organizações onde se constatem elementos das duas formas de racionalidade - instrumentale substantiva -, quaisquer que sejam suas proporções, podem ser produtivas e rentáveis. No entanto, o uso da razão instrumental de maneira excessiva pode deteriorar as relações humanas, ficando esquecidas as dimensões ética e valorativa. Por outro lado, se predomina a ação racional substantiva - apesar de proporcionada uma atmosfera favorável à autorrealização e à satisfação pessoal dos indivíduos que compõem a organização, gerando maior agilidade, flexibilidade e criatividade (FRAGA, 2000) -, a rentabilidade pode ficar comprometida. Esse autor conclui que devem existir pontos de equilíbrio entre as duas racionalidades, enquanto estas forem as orientadoras das ações nas organizações.

Levando em conta essas considerações, a racionalidade será a base para analisar-se a lógica das práticas 
de recursos humanos que efetivamente promovam a igualdade de oportunidades para os indivíduos com deficiência intelectual no mercado de trabalho.

\section{PRÁTICAS DE GESTÃO DE PESSOAS E RACIONALIDADE}

Nas organizações atuais, assiste-se à hegemonia de uma ideologia de gestão que coloca as práticas gerencialistas acima de todos os outros valores sociais, constituindo-se no poder que domina a sociedade atual.

Gaulejac (2007) afirma que a maioria dos manuais de gestão tem como pressuposto que a empresa é um conjunto de fatores que interagem, sendo importante analisar as funções que fazem esse sistema funcionar. Tais funções definem as diferentes especialidades que constituem a ciência da gestão (finanças, marketing, estratégia, contabilidade etc.). Entretanto, há um fator que apresenta problemas particulares, o fator humano, o que torna a gestão de pessoas central entre as preocupações dos gestores. Essa perspectiva traz, no seu bojo, dois pressupostos raramente explicitados: o de que o humano é um fator da empresa e o de que o humano é um recurso da empresa. É possível ilustrar esse argumento com a definição de Dessler (2003) acerca da gestão de pessoas nas organizações atuais. O autor refere-se a ela como:

\footnotetext{
As práticas e as políticas necessárias para conduzir os aspectos relacionados às pessoas no trabalho de gerenciamento, especificamente, à contratação, ao treinamento, à avaliação, à remuneração e ao oferecimento de um ambiente bom e seguro aos funcionários da empresa (DESSLER, 2003, p. 2).
}

Segundo Pagès e outros (2006, p. 98), as práticas citadas por Dessler são essencialmente práticas de poder que se caracterizam por serem fundamentalmente ideológicas e cuja função é interiorizar certas condutas e, ao mesmo tempo, os princípios que as legitimam.

As práticas a que Dessler (2003) se refere fazem parte do dia a dia das empresas. Elas envolvem procedimentos que Pagès e outros (2006) chamam de dispositivos e que compõem os processos do denominado sistema de gestão de pessoas: processos de recrutamento e seleção, de treinamento e de avaliação de desempenho.
Para uma aproximação entre o quadro teórico e o objeto específico deste estudo, são analisados os processos que constituem as práticas de recursos humanos nas organizações atuais, da perspectiva da igualdade de oportunidades para pessoas com deficiência intelectual no mercado de trabalho, tendo em vista a racionalidade a elas subjacente.

\section{Recrutamento e seleção de pessoas com deficiência intelectual}

A análise de cargo tem importância destacada na fase de recrutamento, é o procedimento que consiste na definição das obrigações dos cargos e das características de quem deve ocupá-los. Tal procedimento tem um papel fundamental na conquista da igualdade de oportunidades (Dessle, 2003). O autor destaca, também, que os empregadores devem elaborar planos específicos que incluam mecanismos de flexibilidade os quais permitam a inserção dessas minorias na empresa.

$\mathrm{O}$ argumento de Dessler vai ao encontro da crítica de Gaulejac às práticas atuais de recursos humanos, que consideram as pessoas como custos a serem ajustados às demandas do mercado de trabalho. Nesse sentido, adaptabilidade, flexibilidade e reatividade são palavras-chave para um bom gerenciamento dos recursos humanos (GAULEJAC, 2007).

Os procedimentos propostos para o recrutamento e seleção excluem o indivíduo, criando uma falsa visão de controle e dando uma, também falsa, aparência científica de eliminação da arbitrariedade e da subjetividade (PAGÈS e outros, 2006). Complementando essa ideia, Gaulejac (2007) diz que a preocupação com a objetivação é louvável, mas colocar a realidade numa equação não ajuda a entender o comportamento dos homens nem a história das organizações.

A pessoa com deficiência intelectual, por sua própria definição, necessita de apoio, por meio de orientações, de supervisão e de ajuda técnica que auxiliem ou permitam compensar uma ou mais de suas limitações funcionais, motoras, sensoriais ou mentais, de modo a quebrar barreiras relativas à mobilidade, à temporalidade e à comunicação.

\section{Treinamento de funcionários com deficiência intelectual}

Treinamento é "um conjunto de métodos usados para transmitir aos funcionários novos e antigos as habilidades necessárias para o desempenho do trabalho" 
(DESSLER, 2003, p. 140). Nessa definição, pode ser observada uma objetivação que, segundo Pagès e outros (2006), se pretende racional e tende a reconhecer o indivíduo apenas em função da sua utilidade para a organização.

Mourão (2004), em seu estudo sobre o impacto de programas públicos de treinamento no trabalho e na geração de emprego, corrobora essa objetivação quando recomenda aos profissionais que atuam na área de treinamento:

- o indivíduo deve ser o centro das mudanças organizacionais, pois, mesmo em casos desfavoráveis (como empregar quem tenha deficiência intelectual nesse momento), o investimento nas pessoas produz resultados capazes de modificar a realidade das organizações e das pessoas;

- modificar as estratégicas de formação de multiplicadores, saindo do foco da capacitação gerencial e incluindo, além dos gerentes, alguns membros da equipe;

- levar para os treinamentos situações da vida prática, ampliando o potencial educativo desses cursos;

- observar se o material didático está adequado à realidade do trabalho;

- considerar aspectos menos relevantes, como localização do treinamento, devido aos efeitos decorrentes.

Constata-se que essas recomendações trazem a competência como a maior referência para o processo de decisão, em que o experto domina as modalidades de elaboração e aplicação dos métodos. Discute-se o como e não o porquê; os meios e não as finalidades. Trata-se de fazer os indivíduos aderirem, moldarem-se à organização (GAULEJAC, 2007).

\section{Avaliação de desempenho dos funcionários com deficiência intelectual}

O processo de avaliação de desempenho do trabalhador com deficiência intelectual implica o desenvolvimento de processos específicos de avaliação de desempenho, visando promover a sua integração, com os colegas e com a chefia, e sugerir adaptações e apoio no seu posto de trabalho. Entretanto, de acordo com Pagès e outros (2006), a avaliação de desempenho nas organizações atuais parte da fixação anual de metas a serem atingidas pelo funcionário, cuja promoção não depende de patrões compreensivos, e sim de uma avaliação objetiva. Para ele, as pessoas são etiquetadas, atribuindo-se notas a elas, em função de seu rendimento no sistema. O argumento de Pagès é reforçado ao se analisar como Dessler (2003) define a avaliação de desempenho, a qual é entendida como:

\footnotetext{
a avaliação da relação entre o desempenho atual ou passado de um funcionário e seus padrões de desempenho. A avaliação de desempenho também presume que os padrões de desempenho foram estabelecidos e que você dará feedback ao funcionário para ajudá-lo a eliminar deficiências de desempenho ou manter seu bom nível de desempenho (Ibidem, p. 172).
}

Dessler (2003) propõe que a avaliação de desempenho deva ser feita por meio de critérios estabelecidos com base na análise de cargos, documentada, observando a lei naquilo que se refere à igualdade de oportunidades. No caso da pessoa com deficiência intelectual, deve-se considerar a existência de limitações na produtividade e, sobretudo, que o trabalhador com deficiência intelectual necessitará de um tempo maior para assimilar a rotina.

Todos os métodos de avaliação de desempenho consistem em classificar os funcionários, atribuindo-lhes medidas, ou seja, definindo seu nível de desempenho (PAGÈS e outros, 2006).

Para Gaulejac (2007), as organizações atuais sofrem de quantofrenia, ou doença da medida, em que igualdade de oportunidades se traduz num item que compõe o indicador motivação. Quem não possui bom desempenho é excluído, e o desempenho é a legitimação diante dessa ameaça de exclusão. Alguns se tornam dóceis, deixando-se instrumentalizar totalmente, enquanto outros são afastados por desempenho insatisfatório, o que leva à exclusão de idosos e de deficientes, enfim, dos mais fracos. A empresa espera que seus empregados sejam fortes, dinâmicos, competentes, disponíveis, seguros de si, capazes de enfrentar as contradições e de atingir resultados sempre mais ambiciosos.

\section{MÉTODO}

Trata-se de um estudo de corte seccional com perspectiva longitudinal, operacionalizado por meio de estudo de caso comparativo com triangulação de dados, associando técnicas de observação de campo, análise documental e aplicação de entrevistas semies- 
truturadas. Este estudo tem uma natureza descritiva e configura-se numa pesquisa qualitativa.

A análise deste estudo é a organização, tendo como unidades primárias quatro organizações privadas com empregados com deficiência intelectual, das quais duas têm fins lucrativos e as outras não têm fins lucrativos. Vale ressaltar, ainda, que o processo de gestão dos funcionários com deficiência intelectual de cada uma dessas instituições é a unidade de observação.

As duas organizações de caráter filantrópico (sem fins lucrativos) estudadas foram a Associação de Pais e Amigos dos Excepcionais (APAE) de Pará de Minas e o Instituto Santa Mônica. As duas organizações têm como atividade principal a defesa dos direitos da pessoa com deficiência intelectual. Quanto às duas organizações com fins lucrativos, foram a Cooperativa dos Granjeiros do Oeste de Minas (Cogran) e a Cooperativa Central dos Produtores de Minas Gerais (Itambé). Devido ao pequeno tamanho da unidade de observação, não foram usadas técnicas de amostragem, trabalhando-se com o universo de interesse.

Os sujeitos da pesquisa foram os gerentes de recursos humanos e de linha, perfazendo um total de seis pessoas, e 19 pessoas com deficiência intelectual empregadas nas organizações estudadas.

\section{Definição das categorias de análise}

A definição constitutiva da variável comunicação surge do próprio entendimento quanto ao que seja uma pessoa com deficiência intelectual. Na visão de Goyos e Araújo (2006), a linguagem (receptiva e expressiva) é um dos principais componentes conceituais do comportamento adaptativo do deficiente intelectual, o que mostra a importância da comunicação para se promover a igualdade de oportunidades a esse público no mercado de trabalho. Nesta pesquisa, a comunicação foi operacionalizada pela identificação de elementos significativos - conforme apresentado no Quadro 1 - como os componentes da comunicação nos processos de recrutamento; de seleção; de treinamento e de avaliação de desempenho.

A análise de cargo é um procedimento que consiste na definição das obrigações inerentes a cada cargo e das características de quem deve ocupá-lo (DESSLER, 2003). A definição dessa variável foi realizada pela identificação de elementos significativos, como modificações ocorridas na descrição do cargo inicial utilizada para o recrutamento, conforme se mostra no Quadro 1.

Os atributos de racionalidade instrumental e racionalidade substantiva foram observados nos indicadores de recrutamento, seleção, treinamento e avaliação de desempenho da pessoa com deficiência intelectual. Estes, quando considerados com base nas categorias analíticas definidas, possuem potencial de verificação que permite organizá-los como aspectos específicos de cada um dos indicadores escolhidos neste estudo. No Quadro 2, explicita-se em que base se deu a alocação de cada atributo para cada indicador de cada uma das categorias analíticas.

\section{Coleta de dados}

As técnicas utilizadas para o trabalho de campo foram:

a) painel com especialistas na colocação de pessoas com deficiência intelectual no mercado de trabalho: validação das perguntas da entrevista por meio de discussão com especialistas na colocação de deficientes no mercado de trabalho;

b) entrevista semiestruturada: entrevistas individuais com foco nos pontos de interesse do estudo. Foram entrevistados os gestores de recursos humanos e os de linha, bem como os funcionários com deficiência intelectual da empresa investigada;

c) diário de campo: observações e reflexões sobre as expressões verbais e as ações dos sujeitos, descrevendo-as e analisando-as criticamente.

O trabalho de campo foi realizado como um momento relacional, específico e prático de mão dupla (MINAYO, 2007). A especificidade do público a ser entrevistado - pessoas com deficiência intelectual exige grande esforço e habilidade do pesquisador na realização das entrevistas. Assim, para que delas possam ser extraídos dados importante para o estudo e a fim de se evitarem relatos falsos por parte dos entrevistados, fez-se necessária, inicialmente, a validação das perguntas formuladas por meio de uma discussão com especialistas em educação profissional que qualificam e inserem esse público no mercado de trabalho. O encontro, promovido especificamente para esse fim pelo autor deste estudo, consistiu numa discussão de grupo e foi realizado no dia 24 de setembro de 2009, contou com a participação de 22 educadores que trabalham no programa de formação para o trabalho da pessoa com deficiência intelectual nas APAEs do Estado de Minas Gerais e teve a coordenação do autor do estudo e de 
uma educadora que coordena esse programa na Federação das Apaes do Estado de Minas Gerais.

A metodologia aplicada para o painel consistiu no envio prévio das perguntas aos especialistas, que as testaram em 14 pessoas com deficiência intelectual nas Apaes, trazendo para a discussão esses subsídios prontos. A realização do painel constou de uma parte introdutória, em que se explanou a pesquisa a ser realizada, bem como a pergunta a ser respondida com o estudo.

Na sequência, três grupos, com oito participantes cada um, foram formados. Cada um desses grupos foi responsável por uma parte do sistema de gestão de pessoas: recrutamento e seleção; treinamento; avaliação de desempenho. Ao final, cada grupo apresentou suas conclusões, as quais foram sistematizadas, tendo como resultado um roteiro de entrevista.

Os participantes desse trabalho fizeram algumas considerações gerais que entenderam ser importantes para a realização das entrevistas com as pessoas com deficiência intelectual. Segundo eles: as perguntas devem ser curtas; as compostas devem ser evitadas; se necessário, explicá-las e simplificá-las; falar devagar; direcionar sem induzir as respostas.

As quatro empresas estudadas foram contactadas, inicialmente, por telefone, para explicações sobre as entrevistas e o posterior agendamento. Cabe ressaltar a pronta adesão das empresas escolhidas e a participação da totalidade dos sujeitos envolvidos na pesquisa.

Inicialmente, a validação das perguntas das entrevistas foi feita por meio de uma discussão com 22 especialistas em educação profissional que qualificam e inserem esse público no mercado de trabalho.

Solicitou-se às organizações que permitissem o acesso aos documentos oficiais referentes à gestão das pessoas com deficiência intelectual, tais como: data da contratação dessas pessoas; sistematização dos processos de recrutamento e seleção; treinamento e avaliação de desempenho. A análise dos documentos oficiais e a das anotações de campo foi fundamental para gerar maior precisão aos resultados.

\section{Técnicas de análise e interpretação dos dados}

Após a fase de coleta, procedeu-se à análise, tendo sido os dados agrupados em duas categorias de análise: comunicação e análise de cargos, relativas aos atributos de racionalidade instrumental e racionalidade substantiva observados nos indicadores definidos.

\section{Quadro 1 - Definição das categorias de análise}

\begin{tabular}{|c|c|c|c|}
\hline \multirow{2}{*}{$\begin{array}{l}\text { Categoria de } \\
\text { Análise }\end{array}$} & \multirow{2}{*}{ Indicadores } & \multicolumn{2}{|c|}{ Atributos } \\
\hline & & Racionalidade Instrumental & Racionalidade Substantiva \\
\hline \multirow{4}{*}{ Comunicação } & $\begin{array}{l}\text { Recrutamento da pessoa com } \\
\text { deficiência intelectual }\end{array}$ & $\begin{array}{l}\text { Procedimentos tradicionais de } \\
\text { recrutamento }\end{array}$ & $\begin{array}{l}\text { Procedimentos alternativos de } \\
\text { recrutamento }\end{array}$ \\
\hline & $\begin{array}{l}\text { Seleção da pessoa com deficiência } \\
\text { intelectual }\end{array}$ & Processo de seleção padronizado & Processo de seleção adaptado \\
\hline & $\begin{array}{l}\text { Treinamento da pessoa com } \\
\text { deficiência intelectual }\end{array}$ & Forma de treinamento padronizada & $\begin{array}{l}\text { Forma de treinamento adequada às } \\
\text { possibilidades do trabalhador com } \\
\text { deficiência intelectual }\end{array}$ \\
\hline & $\begin{array}{l}\text { Avaliação de desempenho da } \\
\text { pessoa com deficiência intelectual }\end{array}$ & $\begin{array}{l}\text { Instrumentos de avaliação } \\
\text { padronizados }\end{array}$ & $\begin{array}{l}\text { Instrumentos de avaliação adaptados } \\
\text { à funcionalidade da pessoa com } \\
\text { deficiência intelectual }\end{array}$ \\
\hline Análise de cargo & Atribuições do cargo & Atribuições do cargo padronizadas & $\begin{array}{l}\text { Adequação das atribuições do cargo } \\
\text { às potencialidades do candidato com } \\
\text { deficiência intelectual }\end{array}$ \\
\hline
\end{tabular}


As entrevistas foram gravadas e depois transcritas. Dessas transcrições, foram retirados fragmentos, alocando-os nas categorias definidas. Nessa etapa final da investigação, os dados foram analisados de maneira interpretativa. Essa análise consistiu numa decomposição dos dados coletados e na busca da relação entre essas partes decompostas. Foi verificado se o material disponível mostrava qualidade no que se refere, principalmente, à clareza dos registros e se era suficiente para a análise (MINAYO, 2007).

Depois de tabulados, os dados da entrevista foram confrontados com as notas feitas no diário de campo e com os dados de documentos oficiais coletados nas organizações estudadas. Isso permitiu uma triangulação

\section{Quadro 2 - Definição dos atributos das categorias de análise}

\begin{tabular}{|c|c|c|c|}
\hline \multirow{2}{*}{$\begin{array}{l}\text { Categoria } \\
\text { de Análise }\end{array}$} & \multirow{2}{*}{ Indicadores } & \multicolumn{2}{|c|}{ Atributos } \\
\hline & & Racionalidade Instrumental & Racionalidade Substantiva \\
\hline \multirow{4}{*}{ Comunicação } & $\begin{array}{l}\text { Análise dos procedimentos } \\
\text { utilizados para } \\
\text { se recrutarem os } \\
\text { trabalhadores com } \\
\text { deficiência intelectual }\end{array}$ & $\begin{array}{l}\text { Os procedimentos utilizados para o } \\
\text { recrutamento colocam de fora o indivíduo, } \\
\text { criando uma falsa visão de controle e uma } \\
\text { falsa aparência científica de eliminação da } \\
\text { arbitrariedade e da subjetividade (PAGĖS } \\
\text { e outros, 2006). Utilizam-se os mesmos } \\
\text { procedimentos de recrutamento para todos } \\
\text { os trabalhadores com ou sem deficiência } \\
\text { intelectual, por exemplo, publicação das } \\
\text { vagas disponíveis em: murais nas empresas } \\
\text { e divulgação em meios de comunicação de } \\
\text { massa. }\end{array}$ & $\begin{array}{l}\text { Os procedimentos utilizados para } \\
\text { o recrutamento levam em conta a } \\
\text { necessidade de apoio que permitam } \\
\text { compensar as limitações funcionais } \\
\text { desse trabalhador, de modo a quebrar as } \\
\text { barreiras da comunicação, permitindo que } \\
\text { a informação de disponibilidade da vaga } \\
\text { chegue ao conhecimento do potencial } \\
\text { candidato com deficiência intelectual. }\end{array}$ \\
\hline & $\begin{array}{l}\text { Análise da linguagem } \\
\text { utilizada no processo de } \\
\text { seleção desses candidatos } \\
\text { com deficiência intelectual }\end{array}$ & $\begin{array}{l}\text { Os procedimentos utilizados para a seleção } \\
\text { consideram as pessoas como custos a serem } \\
\text { ajustados às demandas do mercado de } \\
\text { trabalho (GAULEJAC, 2007). Utilizam-se, por } \\
\text { exemplo, os mesmos testes e técnicas de } \\
\text { entrevistas para os candidatos com e sem } \\
\text { deficiência. }\end{array}$ & $\begin{array}{l}\text { A linguagem dos procedimentos de } \\
\text { seleção é adaptada e flexibilizada de } \\
\text { acordo com as limitações funcionais do } \\
\text { candidato, permitindo a compreensão } \\
\text { e assimilação pelo candidato das } \\
\text { informações que estão sendo passadas. }\end{array}$ \\
\hline & $\begin{array}{l}\text { Análise das técnicas de } \\
\text { treinamento utilizadas } \\
\text { para que o trabalhador } \\
\text { com deficiência intelectual } \\
\text { aprenda o serviço }\end{array}$ & $\begin{array}{l}\text { Utiliza os mesmos métodos para todos os } \\
\text { trabalhadores, com ou sem deficiência } \\
\text { intelectual, para transmitir as habilidades } \\
\text { necessárias para o desempenho do trabalho } \\
\text { (DESSLER, 2003). }\end{array}$ & $\begin{array}{l}\text { Utiliza métodos de treinamento que } \\
\text { discutam o como e não por quê; os meios } \\
\text { e não as finalidades, fazendo com que as } \\
\text { organizações se moldem aos indivíduos, e } \\
\text { não o contrário (GAULEJAC, 2007). }\end{array}$ \\
\hline & $\begin{array}{l}\text { Análise dos instrumentos } \\
\text { utilizados para avaliar o } \\
\text { funcionário com deficiência } \\
\text { intelectual }\end{array}$ & $\begin{array}{l}\text { Os instrumentos de avaliação utilizados } \\
\text { partem da fixação anual de metas a serem } \\
\text { atingidas pelo funcionário, cuja promoção não } \\
\text { depende de patrões compreensivos, e sim } \\
\text { de uma avaliação objetiva (PAGĖS e outros, } \\
\text { 2006). }\end{array}$ & $\begin{array}{l}0 \text { instrumento de avaliação utilizado tem } \\
\text { como foco promover a integração do } \\
\text { funcionário com os colegas e com a chefia } \\
\text { e sugerir adaptações e apoio no posto de } \\
\text { trabalho do funcionário com deficiência } \\
\text { intelectual. }\end{array}$ \\
\hline $\begin{array}{l}\text { Análise de } \\
\text { cargo }\end{array}$ & $\begin{array}{l}\text { Análise das adaptações } \\
\text { das tarefas de acordo com } \\
\text { a funcionalidade da pessoa } \\
\text { com deficiência intelectual }\end{array}$ & $\begin{array}{l}\text { Não se adapta às atribuições de acordo } \\
\text { com as possibilidades do candidato com } \\
\text { deficiência intelectual. }\end{array}$ & $\begin{array}{l}\text { Adaptam-se as atribuições do cargo } \\
\text { às potencialidades do candidato com } \\
\text { deficiência intelectual. }\end{array}$ \\
\hline
\end{tabular}


de informações, garantindo a confiabilidade dos fatos observados e expostos nesta investigação.

De acordo com os objetivos estabelecidos para esta pesquisa, foi feito um levantamento da estrutura atual do setor de gestão de pessoas das empresas investigadas, verificando se houve alguma adaptação quando da inserção de funcionários com deficiência intelectual e se foi caracterizado o tipo de racionalidade que orientou essas adaptações. No decorrer desse procedimento, foi apontado tanto o que é homogêneo quanto o que se diferencia no meio social (MINAYO, 2007).

Esse é um processo complexo e não linear que implicou um trabalho de redução, organização e interpretação dos dados, o qual se iniciou já na fase exploratória e acompanhou toda a investigação, observando-se, especificamente os seguintes passos:

1. Catalogação dos dados obtidos com base no processo de observação e anotações de campo;

2. Catalogação dos dados obtidos nos documentos oficiais das empresas estudadas;

3. Registro da ocorrência de dados de cada uma das categorias, indicadores e atributos de racionalidade instrumental e de racionalidade substantiva, em cada uma das entrevistas;

4. Revisão e confrontação dos dados catalogados para conferir a ocorrência dos atributos de racionalidade instrumental ou de racionalidade substantiva em cada um dos indicadores das duas categorias propostas: comunicação e análise de cargo, com base no arcabouço teórico advindo da fundamentação teórica.

Ao final do processo de análise de dados, as informações estavam agrupadas com base nas categorias, indicadores e atributos, permitindo uma compreensão global do tema.

Depois de tabulados, os dados da entrevista foram confrontados com as notas feitas no diário de campo e com os dados de documentos oficiais coletados nas organizações estudadas. Isso permitiu a triangulação de informações.

\section{RESULTADOS E DISCUSSÃO}

Os resultados demonstram como se dá a gestão das pessoas com deficiência intelectual, analisando os indicadores de recrutamento e seleção, de treinamen- to, de avaliação de desempenho e as atribuições de cargo, na perspectiva da racionalidade como conceito central para definição das organizações do trabalho.

\section{Recrutamento e seleção dos trabalhadores com deficiência intelectual nas organizações estudadas}

As organizações com fins lucrativos estudadas não realizam o processo de recrutamento e seleção de trabalhadores com deficiência intelectual. Elas acionam as instituições que trabalham com a formação desse público para o trabalho, indicam o perfil pretendido para a vaga e solicitam que a instituição envie o candidato adequado. Podemos constatar esse fato pela seguinte afirmação de um dos entrevistados:

\begin{abstract}
Elas [as pessoas com deficiência intelectual] já vêm totalmente encaminhadas pela instituição. A gente passa o perfil, as atividades. Quando há necessidade, além do fator de inclusão, a gente tem que manter uma cota mínima, por exigência legal. A gente sempre entra em contato e solicita essas pessoas (Ana Paula - coordenadora de recursos humanos).
\end{abstract}

Se, ocasionalmente, um candidato com deficiência intelectual toma conhecimento de um processo de seleção que esteja acontecendo numa organização com fins lucrativos e, espontaneamente, decide procurá-la, ao ser identificado como deficiente intelectual - em geral, quando o próprio se autorrefere - as instituições que trabalham com a formação desse público são acionadas. Conforme podemos constatar no depoimento da supervisora de recursos humanos da Itambé:

\footnotetext{
Um candidato enviou seu currículo para participar da seleção e, durante o processo, disse que era deficiente intelectual. Então acionamos a instituição que trabalha com esse público, pois ele, em algum momento, já devia ter passado por lá... (Paula de Souza - supervisora de recursos humanos).
}

Em geral, a organização com fins lucrativos que emprega esse público tem uma relação com essas instituições nas localidades onde atuam.

Nas organizações sem fins lucrativos, esses candidatos são recrutados e selecionados dentro da própria instituição entre os alunos que fazem parte do programa de formação para o trabalho: "Antigamente... eu [...] estudava aqui na APAE. Eu não queria sair da APAE..." 
(Renato - trabalhador com deficiência intelectual da APAE de Pará de Minas)..

Nas organizações sem fins lucrativos, o processo de seleção é realizado colocando-se a pessoa numa situação real de trabalho, para ver se ela se adapta à função, dando-lhe o apoio necessário para tanto, conforme aponta o depoimento de Darnely Pinto Coelho, gerente do setor educacional da APAE de Pará de Minas:

Havia alguma coisa errada: o professor pontuava com a gente... Existia problema emocional, que a maioria possuía: a psicóloga estava atenta. A assistente social fazia um trabalho com a família. Fazemos todo um acompanhamento para dar certo (Darnely Pinto Coelho - gerente de setor).

No entanto, na pesquisa de campo, ficou claro que, mesmo com as adaptações realizadas para o entendimento do candidato e apesar de as organizações disporem de mecanismos de acompanhamento melhores, como profissionais que conhecem profundamente esse público (psicólogos, fonoaudiólogos, médicos e outros), os interesses da organização, ou seja, a produtividade desse funcionário, permanecem como o objetivo central do processo de seleção, confirmando a afirmação de Pagès e outros (2006). Essa informação pode ser evidenciada nos trechos do depoimento de Fabiana Drumond, terapeuta ocupacional do Instituto Santa Mônica:

Ela [pessoa com deficiência intelectual] trabalhava na cozinha: não deu certo, não tinha bom desempenho... Estava totalmente desestruturada.

Ele [a pessoa com deficiência intelectual] começou aqui atendendo telefone. Não deu conta. Passou para serviços gerais... Vai limpar só as salas. Não dá conta de limpar o prédio todo.

O estudo demonstra, ainda, que, em todas as organizações pesquisadas, não há nenhuma flexibilidade expressiva nas atribuições dos cargos existentes para promover a inserção dessas pessoas nos postos de trabalho. As características do cargo já estão estabelecidas, e a instituição formadora seleciona, entre seus alunos, aquele que tem possibilidade de ocupar o cargo com eficiência. Consideram, apenas, algumas limitações, muito mais por medo de acidentes de trabalho e de a organização ser acionada legalmente do que devido à pessoa. Essa evidência pode ser constatada no fragmento da entrevista com o gerente de produção da Cogran, a seguir:

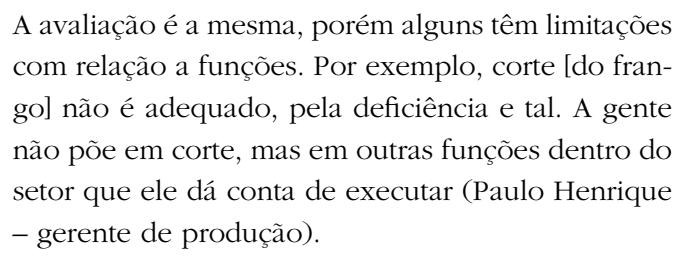

Desse modo, é reafirmada a colocação de Gaulejac (2007), para quem as atuais práticas de recursos humanos ajustam as pessoas às demandas do mercado de trabalho, o que, segundo Dessler (2003), é um entrave à conquista da igualdade de oportunidade para esse público nas organizações do trabalho.

Como podemos constatar, a adequação no processo de recrutamento e seleção dos trabalhadores dá-se apenas quanto aos procedimentos, em relação aos quais as organizações com e sem fins lucrativos estudadas buscam o apoio de especialistas em deficiência intelectual para sua realização. No entanto, a lógica desse processo, com base no desempenho e na meritocracia, é conservada, coibindo a igualdade de oportunidades dessas pessoas no mundo do trabalho.

A seguir, demonstraremos os resultados observados no processo de treinamento desses trabalhadores.

\section{Treinamento dos trabalhadores com deficiência intelectual nas organizações estudadas}

A pesquisa de campo mostra que, nas organizações estudadas, a forma de treinamento utilizada é a realizada no trabalho. Nenhum dos funcionários com deficiência intelectual chegou treinado às organizações, conforme evidencia o trecho do depoimento do gerente de produção da Cogran: "São 30 dias o primeiro período de experiência, podendo ser aumentado por mais 60. Então, dá 90 dias de experiência. Durante esse período, eles são treinados, como os outros, dentro do setor" (Paulo Henrique Pena).

Nessa forma de treinamento, o funcionário que se adequar continua empregado. Por outro lado, aquele que não se adaptar ao serviço não passará do período de experiência. Portanto, esse dispositivo, para o treinamento de situação de vida prática, continua trazendo a competência como maior referência para o processo de decisão. Pode-se constatar essa evidência pelo seguinte fragmento de entrevista: 


\begin{abstract}
A gente vai treinando, o funcionário cumpre as normas da empresa, questão de horário, mais questão de normas internas; executa o serviço de maneira adequada, com qualidade, [então,] ele passa pelo processo de experiência como um funcionário normal e continua trabalhando com a gente (Paulo Henrique Pena - gerente de produção).
\end{abstract}

Deve ser observado que a discussão gira em torno dos meios, e não das finalidades (GAULEJAC, 2007), pois uma pessoa não precisa necessariamente fazer um trabalho tal como este vem sendo realizado. Ela pode atingir o mesmo resultado recorrendo a outros meios, de acordo com suas possibilidades. Diante disso, é possível afirmar que, na utilização desse dispositivo, não ocorre qualquer adequação na comunicação para um melhor entendimento do processo de treinamento por parte desses empregados.

No entanto, nas organizações sem fins lucrativos estudadas, foram observadas algumas adaptações de comunicação nesse processo, pelo fato de essas organizações possuírem, no seu quadro de funcionários, técnicos (psicólogos, fonoaudiólogos, professores e assistentes sociais, entre outros) que fazem um acompanhamento desses trabalhadores e podem ser acionados quando houver necessidade. Em uma das organizações sem fins lucrativos pesquisada, o Instituto Santa Mônica, é disponibilizado outro funcionário, que acompanha um dos trabalhadores com deficiência intelectual, para auxiliá-lo, se necessário, conforme depoimento a seguir: "Ele não sabe, às vezes, para onde ele vai... Há sempre uma pessoa bem próxima para orientá-lo" (Fabiana Drumond - terapeuta ocupacional).

A utilização do dispositivo de treinamento pelas organizações sem fins lucrativos aproxima-se, apesar de muito pouco, da afirmação de Gaulejac (2007) de que o desenvolvimento das organizações só faz sentido se estiver a serviço da vida humana, apresentando, assim, um traço de racionalidade com base nos valores que deveriam balizar as ações sociais nesse tipo de organização. Mesmo assim, conforme citado anteriormente, o número de funcionários com deficiência intelectual nessas organizações é muito pequeno, o que nos leva a pensar não ser tão simples a adequação desse dispositivo para melhor inserção dessas pessoas no mundo do trabalho.

O depoimento anterior demonstra uma maior preocupação por parte dessas organizações para que, de fato, a pessoa com deficiência se adapte e apreenda seu trabalho. Como podemos perceber, essas organizações dispõem, em seus quadros profissionais, de especialistas nesse tipo de deficiência, possibilitando tal adequação. Pensarmos que essa mesma estrutura possa ser montada por organizações com fins lucrativos nos parece, no mínimo, ingênuo, já que aumentariam, sobremaneira, os custos com treinamento.

A utilização dos dispositivos de recrutamento, de seleção e de treinamento possibilita inserir poucos trabalhadores com deficiência intelectual nas organizações estudadas, sejam elas com ou sem fins lucrativos, e, mesmo assim, na medida da lei de cotas. Na próxima seção, será mostrado como ocorre a avaliação desses poucos empregados com deficiência intelectual nas organizações estudadas.

\section{Avaliação de desempenho dos trabalhadores com deficiência intelectual nas organizações estudadas}

Os dados coletados na pesquisa de campo indicam que, nas organizações com fins lucrativos estudadas, a avaliação de desempenho desses funcionários é feita por meio dos mesmos dispositivos utilizados para os funcionários sem deficiência intelectual, conforme trecho de entrevista com a coordenadora de recursos humanos da Cogran:

[...] tanto o critério da empresa como o meu é que, para a gente, eles são normais. Não há distinção ou diferenciação. As mesmas condições oferecidas entre os ditos normais são oferecidas para eles. Acho que é disso que eles precisam, serem vistos como normais... Se ele grita lá dentro [do setor de trabalho], se ele taca um frango numa outra pessoa e não acontece nada com ele... pode pensar que pode agir dessa maneira, que nada vai lhe acontecer, porque é deficiente... Ele pode se esconder atrás dessa deficiência... É necessário mostrar que ele pode ter deficiência, mas é normal. Se fez coisa boa, vai ter lucro, mas, se fez coisa que não devia, vai ser punido da mesma forma que qualquer outro funcionário seria punido (Ana Paula - coordenadora de recursos humanos)

Esse depoimento mostra uma total falta de conhecimento desse público pela organização com fins lucrativos, pois não considera a diversidade de seus funcionários e trata os desiguais de modo igual. Esse resultado observado reafirma o argumento de Pagés e outros (2006) de que, nas organizações atuais, a 
avaliação de desempenho não depende de patrões compreensivos, e sim de uma avaliação objetiva, fato que também é confirmado pelo depoimento da supervisora de recursos humanos da outra organização com fins lucrativos estudada, a Itambé: "Utilizamos o mesmo processo de avaliação de desempenho que a empresa tem. Avaliamos o comportamento, a produtividade deles" (Paula de Souza - supervisora de recursos humanos).

No que se refere às organizações sem fins lucrativos, observou-se, na pesquisa de campo, que quatro dos cinco funcionários que hoje trabalham no Instituto Santa Mônica já trabalharam em organizações com fins lucrativos, das quais foram dispensados, sob justificativa de inadequação ao serviço. No entanto, essas mesmas pessoas hoje exercem suas funções em uma organização sem fins lucrativos, onde sua avaliação é positiva, apontando para uma adequação do processo de avaliação realizado: "Já trabalhei lá dentro da Inconfral [organização com fim lucrativo que a contratou], só que não deu certo" (Marciléia do Carmo - funcionária com deficiência intelectual).

Essa funcionária é contratada por uma organização com fins lucrativos, mas exerce suas funções numa organização sem fins lucrativos. Nessa organização, o Instituto Santa Mônica, dos cinco funcionários que exercem as mesmas funções, quatro são contratados pela mesma organização com fins lucrativos, segundo depoimento da terapeuta Fabiana Drumond:

$\mathrm{Na}$ contratação, eles foram à empresa [Inconfral], conversaram com o setor de lá. Eles usam o uniforme de lá [...] Sempre coloco para eles que trabalham aqui, mas são pagos pela empresa [...] Eles assinam o ponto que é apresentado pela empresa [Inconfral].

A gestão dessas pessoas é feita por essa profissional, por meio de reuniões semanais, não recorrendo aos dispositivos de avaliação de desempenho utilizados pelas organizações com fins lucrativos.

A análise do processo de avaliação de desempenho aponta para uma inadequação desse processo pelas organizações com fins lucrativos e para ajustes efetuados pelas organizações sem fins lucrativos, seja porque compreendem melhor as necessidades desses funcionários, seja porque contam com esses profissionais (psiquiatras, psicólogos clínicos e fonoaudiólogos) em seus quadros, para os encaminhamentos necessários.
Salienta-se o fato de que, se os encaminhamentos descritos anteriormente são fundamentais para uma satisfatória avaliação desses funcionários, implicam um aumento considerável de custos para que as organizações com fins lucrativos se adequem, exigindo uma ampliação dos seus setores de recursos humanos por meio de outras contratações para que, de fato, possam realizar a gestão desses empregados.

\section{CONCLUSÕES}

O debate sobre a inserção da pessoa com deficiência intelectual nas organizações do trabalho é uma questão de difícil compreensão e que envolve várias contradições. Porém, quando levado a cabo de maneira correta, norteia-se pelo esforço para se definir, de maneira cada vez mais precisa, aquilo que está sendo debatido, para que, de fato, possamos empreender esforços para a promoção da igualdade de oportunidade para esse público no mercado de trabalho.

Ao conectar-se o pressuposto, discutido na fundamentação teórica, de que a racionalidade é o conceito central para definirmos uma organização com os resultados obtidos na pesquisa de campo, observa-se que, nas organizações estudadas (com e sem fins lucrativos), são encontrados elementos apenas de racionalidade instrumental. Isso ocorre se considerarmos o tipo ideal weberiano, segundo o referencial teórico proposto por Kalberg (1980), pois a ação social dentro dessas organizações é centrada na relação meio-fim. Mesmo se, como Fraga (2000) e Serva (1997), acreditarmos que há pontos de equilíbrio entre a racionalidade instrumental e a substantiva, vistas como orientadoras das ações nas organizações, o estudo da inserção da pessoa com deficiência intelectual no mercado de trabalho aqui realizado demonstra que, num continum, todas as organizações aqui analisadas baseiam suas práticas de gestão de pessoas muito mais na instrumentalidade do que em valores nos quais os resultados não interessariam.

Nas organizações com fins lucrativos estudadas, predomina a formalização mecanicista. Nelas, a pessoa com deficiência intelectual tem de atender aos interesses da organização, considerando-se todos os indicadores analisados: recrutamento e seleção, treinamento, avaliação de desempenho e as atribuições descritivas do cargo.

Nas organizações sem fins lucrativos, apesar de 
detectarmos algumas adequações de procedimentos, a essência mecanicista de produtividade do funcionário prevalece. Assim, a avaliação de desempenho positiva parece decorrer muito mais do fato de tratar-se de organizações que trabalham pela defesa desse público minoritário do que pelo entendimento de que atores sociais dentro da organização possam ter um modo particular de atingir os mesmos fins. Isso caracterizaria a predominância de uma racionalidade substantiva que definiria, conforme discussão teórica realizada, esse tipo de organização.

Apoiando-se nessas conclusões, é possível verificar que as práticas de recursos humanos, nas organizações estudadas, têm que se modificar bastante para, de fato, serem promotoras da igualdade de oportunidade para o trabalhador com deficiência intelectual.

Vale ressaltar que os trabalhadores com deficiência intelectual ocupam os cargos mais baixos na hierarquia organizacional e, devido a sua gênese, são discriminados pelos trabalhadores que ocupam o mesmo cargo que eles, que consideram os deficientes inferiores pelas suas limitações cognitivas, criando-se, assim, a nova ralé das organizações do trabalho.

\section{REFERÊNCIAS}

AMERICAN ASSOCIATION ON MENTAL RETARDATION. Retardo mental: definição, classificação e sistema de apoio. Tradução: Magda França Lopes. 10. ed. Porto Alegre: Artmed, 2002.

DESSLER, G. Administração de recursos bumanos. Tradução: Cecília Leão Oderich. São Paulo: Rearson, 2003.

DiAS, A. F; DEllagnelO, E. H. L. Práticas organizativas de grupos de cultura popular: das burocracias aos modelos alternativos de gestão. In: ENCONTRO DA ASSOCIAÇÃO NACIONAL DE PÓS-GRADUAÇÃO E PESQUISA EM ADMINISTRAÇÂO, 32, 2008, Rio de Janeiro. Anais. Rio de Janeiro: ANPAD, 2008.

FRAGA, M. L. A empresa produtiva e a racionalidade substantiva. Dissertação de Mestrado em Administração, Universidade Federal do Rio Grande do Sul, Porto Alegre, 2000.

GAULEJAC, V. de. Gestão como doença social: ideologia, poder gerencialista e fragmentação social. Tradução: Ivo Storniolo. São Paulo: Ideias \& Letras, 2007.
GOYOS, C; ARAÚJO, E. A. C. (Org). Inclusão social: formação do deficiente mental para o trabalho. São Carlos: Rima, 2006.

KALBERG, S. Max Weber's types of rationality: cornerstones for the analysis of racionalization process in history. American Journal of Sociology, v. 85, n. 5, 1980.

KANT, I. Crítica da razão pura. Tradução: Manuela Pinto dos Santos e Alexandre Fradique Morujão. Lisboa: Fundação Calouste Gulbenkian, 1989.

MINAYO, M. C. de S. (Org). Pesquisa social: teoria, método e criatividade. 26. ed. Petrópolis: Vozes, 2007.

MOURÃO, L. Avaliação de programas públicos de treinamento: um estudo sobre impacto no trabalho e na geração de emprego. Tese de Doutorado em Psicologia, Universidade de Brasília, Brasília, 2004.

PAGÈS, M. e outros. O poder das organizações. Tradução: Maria Cecília Pereira e Sonia Simas Favatti. São Paulo: Atlas, 2006.

RAMOS, A. G. Administração e contexto brasileiro: esboço de uma teoria geral da administração. 2. ed. Rio de Janeiro: FGV, 1983. cap. 2, p. 36-51.

SERVA, M. A racionalidade substantiva demonstrada na prática administrativa. RAE-Revista de Administração de Empresas, v. 37, n. 3, p. 18-30, 1997.

VIEIRA, M. M. F. Organizações culturais. Rio de Janeiro: EBAPE/FGV, 2008. (Working paper.).

WEBER, M. Sociologia de la dominación. In: WEBER, Max. Economia y sociedade. México: Fondo de Cultura Económica, 1983. p. 695-1117.

\section{NOTA DA REDAÇÃO}

A RAE publica este artigo in memoriam do prof. Marcelo Milano Falcão Vieira, que prestou valiosa colaboração nos processos editoriais da $R A E$, como autor e como avaliador ad hoc. Contamos com os professores Carlos Osmar Bertero e Rafael Alcadipani em agradecimento e homenagem que prestamos ao prof. Marcelo Milano Falcão Vieira, na página a seguir. 


\section{Homenagem ao Prof. Marcelo Milano Falcão Vieira (in memoriam)}

Graduado em contabilidade pela Universidade Federal do Rio Grande, o Prof. Marcelo Milano concluiu seu mestrado na Universidade Federal de Santa Catarina, no ano de 1989. Na sequência, concluiu seu PhD na Universidade de Edimburgo, em 1996. Mais recentemente, fez pós-doutoramento na École de Hautes Études Commercialles, em Paris. O Prof. Marcelo Milano dedicou sua vida a compreender as organizações em sua dimensão institucional e de poder. Entre os diferentes temas dos seus escritos, destacou-se ao buscar trazer a questão do poder para as discussões em Teoria Institucional no Brasil, fazendo com que essa perspectiva teórica assumisse um ar menos conservador. Além disso, sobressaiu também por dedicar-se a estudar as dinâmicas de organizações culturais, algo que fez com bastante sucesso. Buscou ajudar no desenvolvimento local e nacional. O Prof. Marcelo constituiu-se como um dos principais acadêmicos da área de Estudos Organizacionais brasileiros e serviu de inspiração para inúmeros pesquisadores. O rigor acadêmico sempre foi uma de suas principais marcas. Um acadêmico interdisciplinar, também contribuiu na área de Geografia, em escritos que teve o privilégio, que raros de nós temos, de produzir em coautoria com seu pai. Ao longo de sua trajetória acadêmica, o Prof. Marcelo publicou mais de 70 artigos em periódicos, foi autor e editou 11 livros, e sempre engrandecia os eventos da área com sua presença. Destacava-se não apenas por sua argumentação aguçada e rigorosa, mas também por sua elegância no trato com os demais e habilidade para questionar aquilo que poucos tinham coragem de fazer. O Prof. Marcelo foi coordenador da divisão de Estudos Organizacionais da Associação Nacional de Pós-Graduação e Pesquisa em Administração (ANPAD) e contribuiu para termos uma academia mais arejada intelectualmente e mais aberta à participação de todos, contribuição essa que é tão importante quanto seus escritos.

Participou de mais de meia centena de bancas de doutorado e mestrado em diferentes universidades de nosso país, além de ter contribuído decididamente com a formação de recursos humanos para a pesquisa brasileira, pois orientou inúmeros estudantes de programas de iniciação científica, mestrado e doutorado. Além disso, foi fundador de um dos principais grupos de pesquisadores da área no Brasil, o Observatório da Realidade Organizacional, mostrando sua capacidade de aglutinação de estudiosos.

Sua participação na $R A E$ foi substancial desde o início, em 2000. Dois de seus livros foram resenhados, inúmeros trabalhos foram publicados, e contribuiu com precisas e delicadas avaliações para este periódico. A RAE tem o orgulho de publicar um de seus últimos escritos, o texto "Pessoa com deficiência intelectual: a nova "ralé" das organizações do trabalho".

Vimos em Marcelo Milano Falcão Vieira um pesquisador e professor completo, exemplo para todos nós. É realmente lamentável que tenha nos deixado tão cedo. Já nos faz muita falta.

\section{Rafael Alcadipani}

Professor da FGV-EAESP

\section{Carlos Osmar Bertero}

Professor da FGV-EAESP 